\title{
Homicidio por parte de conductores de vehículos automotores en estado de embriaguez
}

\author{
Homicide while driving a motor vehicle while intoxicated \\ Homicídio de condutores de veículos automóveis em um estado de embriaguez
}

DOI: https://doi.org/10.21803/penamer.13.26.420

\section{Jhonfer Palacios Rengifo \\ https://orcid.org/0000-0003-0298-1749 \\ Wendy Vanessa Rueda Sánchez \\ https://orcid.org/0000-0002-3368-4803}

\section{¿Cómo citar este artículo?}

Palacios, J. \& Rueda, W. (2020). Homicidio por parte de conductores de vehículos automotores en estado de embriaguez. Pensamiento Americano, 13(26), 51-61.

DOI: https://doi.org/10.21803/penamer.13.26.420

\begin{abstract}
Resumen
Los reiterados y ya habituales casos de muertes a causa de conductores ebrios en el pais, han generado naturalmente un rechazo de la sociedad, esto porque en la mayoría de los casos las consecuencias son catastróficas, ya que, casi siempre termina la víctima con la afectación de uno de los órganos y/o extremidades o en el peor de los casos y cómo podemos evidenciar en nuestro diario vivir con la misma muerte. El derecho penal no ha sido ajeno a centrar su mirada en aquellos presupuestos fácticos, habida cuenta que, el poder punitivo del Estado, en procura de salvaguardar los bienes jurídicos de sus ciudadanos debe intervenir en circunstancias en las cuales exista lesión o riesgo para el bien jurídicamente tutelado "VIDA E INTEGRIDAD PERSONAL", concretamente, la Corte Suprema de Justicia (proceso 32964 de 2010), tras pronunciarse respecto del tratamiento punitivo que debería darse a los autores de dichas conductas, sugirió una interpretación que para los jueces, y dogmáticos del derecho penal, ha desencadenado todo tipo de debates donde encontramos adeptos y detractores, amores y desamores, en el sentido, que para algunos estudiosos del dogma penal es una interpretación demasiado amplia en la que se pueden presentar ambigüedades. En este escrito realizaremos un análisis claro y profundo para así poder responder que tipo de imputación subjetiva consideramos debe atribuirse a un sujeto que comete un homicidio conduciendo un vehículo automotor en estado de embriaguez.
\end{abstract}

Palabras clave: Dolo, culpa. Dogma, alcohol, ebriedad, conducta, pensamiento, normas, conducta, deseo, finalidad, imputación, voluntad, penas, plausible y conductas.

\begin{abstract}
The repeated and already common cases of deaths due to drunk drivers in the country have naturally generated a rejection of society, this because in most cases the consequences are catastrophic, since the victim almost always ends up with the affectation of one of the organs and / or extremities or in the worst case and how we can show in our daily living with the same death. Criminal law has not been oblivious to focusing its gaze on those factual assumptions, taking into account that, the punitive power of the State, in an attempt to safeguard the legal rights of its citizens, must intervene in
\end{abstract}

\footnotetext{
*Artículo de grado para optar al título de abogado Universidad Tecnológica del Chocó “Dlc” Facultad de Derecho Quibdó trabajo de grado o modalidad.
} 
circumstances in which there is injury or risk to good legally protected "LIFE AND PERSONAL INTEGRITY", specifically. The Supreme Court of Justice (process 32964 of 2010), after ruling on the punitive treatment that should be given to the perpetrators of said conduct, suggested an interpretation that for the judges, and dogmatists of criminal law, it has triggered all kinds of debates where we find supporters and detractors, loves and heartbreaks, in the sense that for some scholars of criminal dogma it is too broad an interpretation in which ambiguities may arise. In this writing we will carry out a clear and deep analysis in order to be able to answer what type of subjective imputation we consider to be attributed to a subject who commits a homicide while driving a motor vehicle while intoxicated.

Keywords: Delinquency, guilt, dogma, alcohol, drunkenness, conduct, thought, norms, conduct, desire, purpose, imputation, will, penalties, plausible and conducts

\section{Resumo}

Os repetidos e já comuns casos de mortes por motoristas embriagados no país, têm gerado naturalmente uma rejeição da sociedade, até porque na maioria das vezes as consequências são catastróficas, já que a vítima quase sempre acaba com a afetação de um dos órgãos e / ou extremidades ou no pior dos casos e como podemos mostrar em nosso convívio diário com a mesma morte. O direito penal não tem esquecido de focar o seu olhar sobre esses pressupostos factuais, tendo em conta que, o poder punitivo do Estado, na tentativa de salvaguardar os direitos jurídicos dos seus cidadãos, deve intervir em circunstâncias em que haja prejuízo ou risco ao bem amparado legalmente "VIDA E INTEGRIDADE PESSOAL", especificamente, o Supremo Tribunal de Justiça (processo 32964 de 2010), após decisão sobre o tratamento punitivo que deveria ser dado aos autores de tal conduta, sugeriu uma interpretação que para os juízes, e os dogmáticos do Direito Penal têm desencadeado todos os tipos de debates onde encontramos partidários e detratores, amores e tristezas, no sentido de que para alguns estudiosos do dogma criminal é uma interpretação muito ampla em que podem surgir ambigüidades. Neste escrito, faremos uma análise clara e aprofundada para podermos responder que tipo de imputação subjetiva que consideramos deve ser atribuída a um sujeito que comete um homicídio enquanto dirige um veículo motorizado embriagado.

Palavras-chave: Dolo, culpa. Dogma, álcool, embriaguez, conduta, pensamento, normas, conduta, desejo, propósito, imputação, vontade, penalidades, plausibilidade e comportamentos.

\section{Perfiles}

Perfil académico del autor, Código ORCID: Estudiante de Derecho Universidad Tecnológica del Chocó

Perfil académico del autor, Código ORCID: Estudiante de Derecho Universidad Tecnológica del Chocó
Jhonfer Palacios Rengifo

Wendy Vanessa Rueda

Sánchez 


\section{Introducción}

En Colombia desde hace muchísimos años se ha padecido por los reiterados y habituales casos de muerte, lecciones y daños materiales por causa de conductores de vehículos automotores en estado de embriaguez, donde ya se tienen sinfín de consideraciones y jurisprudencia sobre esta y los daños que ocasionan.

Para este tipo de casos los jueces pueden, aplicarle la pena del dolo a quien actúa sin dolo - responsabilidad objetiva, proscrita en el ordenamiento jurídico penal colombiano, artículos 9 y 12 del código penal - lo que no puede es convertir en doloso lo que es culposo.

No es tarea de los jueces satisfacer demandas de la sociedad motivadas en el incremento de las muertes por accidentes de tránsito, a través de dudosas interpretaciones legales que ven en el dolo eventual una forma de incrementar la penalidad pues, los jueces no pueden arrogarse indirectamente facultades legislativas.

Por franqueza académica debemos expresar que el problema vislumbrado no es inédito, por el contrario, la doctrina desde la época pasada se ha preocupado por el tema, como mencionaron los profesores Fernández Carrasquilla; Nódier Agudelo, Gerardo Paz, entre otros, que en trabajos precedentes han expresado soluciones jurídicas de acuerdo a un sin número de variables, así, el destacado miembro del Grupo Medellín, expresó:

Quien se embriaga para delinquir debe responder a título doloso por el hecho; quien se embriaga previendo el hecho, y lo acepta, debe responder por dolo eventual; quien se embriaga voluntariamente con previsión del hecho, previendo el hecho, responde a título de culpa, sea que haya o no tenido la intención de ejecutarlo (Agudelo Betancur, 2004)

De conformidad con las hipótesis fácticas planteadas, sostiene, el contenido de la voluntad hay que referirlo al delito cometido y no al hecho mismo de la ingesta y no puede confundirse la voluntad de la embriaguez con la voluntad del hecho punible (Agudelo Betancur, 2004)

De acuerdo a lo anterior, el único mérito que puede tener el acápite de este trabajo es quizá en la delimitación del tipo penal - La doctrina estudió, de manera general, la embriaguez y responsabilidad penal, o de alcohol y delito - habida cuenta que se analizará la imputación subjetiva en el tipo penal de homicidio, consagrado en la art 103 del Estatuto Punitivo colombiano, pues frente a las lesiones personales consagradas en el artículo 111, la judicatura no vacila en adecuar típicamente la conducta del conductor embriagado en el artículo 120, que consagra el tipo penal de lesiones culposas.

Ahora bien, se ha señalado que de los aspectos más difíciles de probar en el proceso penal es la intención. Oigamos al profesor Vives Antón: el hecho de que un tercero pueda conocer mis verdaderas intenciones mejor que yo mismo porque, conociendo mi conducta, sepa mejor que yo lo que voy hacer, esto es, lo que realmente quiero.

Para que esto último sea posible, es decir, para que otra persona, observador de mi conducta externa, pueda saber mejor que yo lo que realmente quiero, es preciso replantearse que es eso del querer (Vives Antón, 2011)

A lo que invita el profesor español, en términos de práctica judicial es, tan sencillo como que, cuando el juzgador avizore una duda con relación a la comisión de un resultado típico y antijurídico, se debe realizar una interpretación, pro homine, que supone la humanización del derecho penal (derecho penal demoliberal) tendiente a atribuir responsabilidad penal al sujeto activo a título culposo. Ello sería concordante con el artículo séptimo del estatuto adjetivo punitivo colombiano, esto es, el principio de la duda en favor del procesado. - imputación subjetiva - con los cuales se producen ciertos resultados antijurídicos, es decir, probar el dolo o la culpa, es una labor que requiere

Pensamiento Americano Vol. 13 - No. 26 - p.p. 51-61 • 2020 • Julio-Diciembre • Corporación Universitaria Americana · Barranquilla, Colombia • ISSN: 2027-2448 http://publicaciones.americana.edu.co/index.php/pensamientoamericano/index 
objetividad y análisis minucioso sobre las circunstancias de tiempo, modo y lugar de producción del resultado lesivo del bien jurídicamente tutelado.

Los eventos en los cuales un sujeto que conduce bajo los efectos del alcohol ocasiona la muerte a un individuo, son susceptibles de determinación de la intención con la cual se presenta el resultado antijurídico -muerte -. Así las cosas, es plausible considerar -inicialmente - que dicho resultado deviene de la imprudencia- conducir bajo los efectos de bebidas embriagantes- del sujeto activo. Se plantea como hipótesis que, las muertes ocasionadas por conductores ebrios, son imputables subjetivamente a título de culpa, y más específicamente, culpa con representación, tal como lo dispone la legislación actual - artículo 109 del código penal y la agravante subsiguiente - pensar en responsabilidad penal a título de dolo, de manera abstracta, resultaría un grave atentado a los avances dogmático penales; supondría, sin vacilación alguna, una abrupta reinvención del estudio de la teoría del delito.

Se señalaba en la introducción que el presente trabajo no tendría razón de ser en la práctica judicial, pues, el artículo 2 de la ley 1696 de 2013 consagró un agravante para el homicidio culposo, veamos: "Si al momento de cometer la conducta el agente estuviese conduciendo vehículo automotor bajo el grado de alcoholemia igual o superior al grado $1^{\circ} \mathrm{o}$ bajo el efecto de droga o sustancia que produzca dependencia física o síquica, y ello haya sido determinante para su ocurrencia, la pena se aumentará de las dos terceras partes al doble, en la pena principal y accesoria”. Concede la razón el legislador - las motivaciones son obvias a aquellos críticos de aquella jurisprudencia legitimadora del dolo eventual; aunque resulte inconcebible para los validadores de la represión a ultranza, la solución dogmática es, precisamente, la consagrada en dicha norma, homicidio culposo agravado, con ello se pone fin a los molestos sofismas de distracción, se respetan los principios de legalidad, presunción de inocencia, del acto y, consecuentemente, se satisfacen los ánimos vindicativos con el aumento punitivo.

\section{El dolo en accidentes de tránsito}

\section{Concepto de dolo}

La esencia del tipo subjetivo está dada por el dolo, entendido como el conocimiento de los elementos objetivos del tipo y la voluntad de transgresión de los mismos.

El dolo como voluntad de hecho, significa, por tanto, voluntad de concreción. "Querer" no quiere decir, en derecho penal, querer "tener" o "alcanzar" (en el sentido aspirado), sino querer “concretar” (Welzel, 1956a).

Refiriéndose al concepto de dolo expresa Zaffaroni:

El núcleo central del tipo subjetivo es el dolo. Dolo es la voluntad realizadora del tipo guiada por el conocimiento de los elementos del tipo objetivo sistémico. el dolo implica el requerimiento de una finalidad típica y, por lo tanto,junto con la culpa importan una limitación al poder punitivo, pues excluyen cualquier posibilidad de responsabilidad objetiva (Zaffaroni, 2011).

En resumidas cuentas, podemos concretar que el dolo se define como conocimiento y voluntad del tipo objetivo. Lo anterior significa que el dolo está conformado por un aspecto cognitivo (conocimiento de los elementos del tipo objetivo) y un aspecto cognitivo (volitivo o voluntad de realización de los elementos del tipo objetivo).

\section{Elementos del dolo}

Los elementos del tipo objetivo son aquellos que describe la acción prohibida u ordenada mediante un verbo rector (conducta ordenada o prohibida), sujetos (activo y pasivo), objeto (material y jurídico) elementos normativos (aquellos definidos por la ley, servidor público, documento, etcétera).

El artículo 22 del Código Penal dice:

La conducta es dolosa cuando el agente conoce 
los hechos constitutivos de la infracción penal y quiere su realización. También será dolosa la conducta cuando la realización de la infracción penal ha sido prevista como probable y su no producción se deja librada al azar. (2000)

Es decir, el dolo se compone de un elemento cognitivo, y otro elemento volitivo dolo bueno o avalorado.

\section{Elemento cognitivo del dolo}

Toda acción consciente es llevada por la decisión de acción, por la conciencia de lo que se quiere - elemento intelectual -. (Welzel, 1956b)

Exige que el sujeto activo debe conocer que realiza el tipo objetivo, o lo que es lo mismo, el agente debe conocer los hechos constitutivos de la prohibición u orden emanada del tipo penal.

El conocimiento debe ser efectivo. Un conocimiento potencial no es tal en el tipo doloso, a diferencia de lo que sucede en el tipo culposo. El autor debe saber que efectivamente disparar contra lo que se sabe es una persona, para que se cumpla con el elemento cognitivo del tipo de homicidio. (Tenca, 2010)

El elemento de cognitivo es útil para deducir una conclusión fiable sobre la decisión en contra del bien jurídico: quien conoce todas las circunstancias dañosa y de todos modos actúa, no podrá afirmar que ello no entra dentro de su decisión (Hassemer, Muñoz Conde, \& Díaz Pita, 1999).

El profesor Zaffaroni expresa que el dolo requiere conocimientos efectivos y actuales, señala:

Los elementos del tipo objetivo sistémico deben ser conocidos en forma efectiva, o sea que deben estar disponibles en la consciencia del agente. No basta con el conocimiento potencial (o posibilidad de conocimiento), que por definición es un no conocimiento que sólo puede transformarse en conocimiento. No basta para el dolo con que el conocimiento sea efectivo: es nece- sario también que se actual. No es actual el dato que está en la memoria pero que no se tiene en cuenta (no se actualiza) en el momento de decidir y actuar (Zaffaroni, 2011).

Luego entonces no basta con que se haya tenido la posibilidad de saber los elementos del tipo objetivo

\section{Elemento volitivo del dolo}

Es necesario, para que se estructure el dolo, además del conocimiento, querer realizar los elementos del tipo objetivo. Es decir, realizar acciones en aras de obtener el resultado o, como diría Welzel (1956a), la decisión de querer realizar la acción final. Dolo es conocimiento y querer de la concreción del tipo.

Ese querer es el aspecto volitivo del dolo. Al igual que en su aspecto cognoscitivo, el volitivo debe estar presente en el momento en que la acción prohibida da comienzo. En este aspecto, cabe destacar que tampoco tiene ninguna validez el dolus antecedens y el dolus subsequens.

Por ejemplo, A planea matar a su vecino B disparándole con un arma en una fiesta que organizará en su casa; pero B muere en la fiesta producto la explosión involuntaria de una garrafa. Por ello ha de responder tan solo por la muerte culposa de B (dolus antecedens). Una idéntica respuesta cabe para el caso en que A ve a una persona en su jardín durante la noche, y en absoluto convencimiento de que se trata de un ladrón dispara, matando a B. al acercarse y descubrir que es su vecino, se pone contento. Así pues, A no deberá responder como autor doloso de la muerte de B. (Tenca, 2010).

Siendo así podemos concluir que debe de existir la intención de realizar el hecho, es decir el querer hacerlo y llevarlo a cabo con total conocimiento de que resultado darán los hechos.

\section{Dolo directo}

También denominado dolo de primer grado. Se

Pensamiento Americano Vol. 13 - No. 26 - p.p. 51-61 • 2020 • Julio-Diciembre • Corporación Universitaria Americana · Barranquilla, Colombia • ISSN: 2027-2448 http://publicaciones.americana.edu.co/index.php/pensamientoamericano/index 
entiende que se está frente a un dolo directo cuando el autor cumple a cabalidad el resultado querido, es decir, realiza a satisfacción el tipo objetivo. La consagración legal de esta tipología se halla en la primera parte del artículo 22 del Código Penal. El profesor Zaffaroni lo ilustra de la siguiente manera, el agente dispara seis balazos contra otra persona para matarlay la mata (Zaffaroni, 2011). Esta tipología de dolo supone, para decirlo en palabras de Frisch, citado por Hassemer, una decisión a favor de la lesión del bien jurídico (Hassemer, Muñoz Conde, \& Díaz Pita, 1999).

De acuerdo con Tenca (2010), en el denominado dolo directo, el agente (Juan) se propone un fin prohibido, matar a Pedro, luego selecciona los medios para obtener el resultado propuesto, compra un arma de fuego, para, finalmente, poner en marcha un proceso causal y con ello materializar la ideación, espera a su víctima a la salida del trabajo y le dispara.

En el tipo doloso lo prohibido, y penado, es la conducta, matar, pues el fin propuesto por el autor es lo que está prohibido. Existe una coincidencia entre lo que el autor hace y lo que el autor quiere. En el obrar doloso la voluntad del autor tiene que dirigirse a la realización del hecho típico no de una manera impersonal sino como su propia obra (Tenca, 2010).

Por consiguiente, cabe decir que el dolo directo requiere de un plan que este articulado por el actor de hecho y que este plan se lleve a cabalidad siguiendo cada uno de los puntos planteados, donde el fin de satisfacer su deseo contra el bien jurídicamente tutelable.

\section{Dolo directo de segundo grado}

También se le conoce como dolo mediato, indirecto o de consecuencias necesarias. Y, es aquél en el cual, la realización del tipo objetivo es la consecuencia necesaria de los medios seleccionados - empleados por el sujeto activo - es aquel en que se presentan dos resultados, i) el querido por el sujeto activo y ii) el no querido por el sujeto activo pero que se va a presentar como consecuencia necesaria de los medios seleccionados para obtener el primer resultado.
Es importante clarificar que en esta tipología de dolo concurren tanto el elemento cognitivo como el volitivo, solo que se presentan dos resultados, en el cual el segundo, posee un menor grado de aspecto volitivo, sin embargo, no hace desaparecer el conato. Al respecto expresa el profesor Tenca.

Cabe mencionar que lo que se conoce como dolo directo de segundo grado, indirecto o dolo de consecuencias necesarias es una modalidad de dolo directo y, por ende, reúne todos y cada uno de sus requisitos. Ello es importante, pues un sector de la doctrina ha pretendido ver en esta clase de dolo un dolo sin voluntad, lo que desde nuestra consideración resulta equivoco. (Tenca, 2010).

Gimbernat Ordeig referiría; donde verdaderamente es difícil ver una voluntad - a pesar de que existe unanimidad en afirmar la punición por dolo - es en los resultados causados con dolo directo de segundo grado, esto es: en aquellos resultados que sin ser el fin de la acción del sujeto se saben necesariamente unidos a lo directamente perseguido. (Ordeig, 1972)

\section{DOLO EVENTUAL}

Se entiende como aquel dolo en el que el sujeto activo se representa como probable que de su conducta se genere un resultado, y no obstante ello, se continúa con la conducta, dejando el resultado librado al azar. Esta figura encuentra regulación normativa en el artículo 22, segunda parte del Código Penal colombiano.

En el dolo eventual (también llamado condicionado) el agente se representa la posibilidad de producción de un resultado, pero encubre su voluntad realizadora acudiendo a una infundada esperanza de que no se produzca. La voluntad realizadora existe en la psiquis del agente, pero este apela al recurso de no saber lo que sabe mediante una esperanza infundada, de modo que la representación de esta posibilidad no le hace desistir de su plan. (Zaffaroni, 2011).

Es decir, en este tipo de dolo el actor prepara la realización de la conducta, pero deja al azar si esta se

Pensamiento Americano Vol. 13 - No. 26 - p.p. 51-61 • 2020 · Julio-Diciembre · Corporación Universitaria Americana · Barranquilla, Colombia • ISSN: 2027-2448 http://publicaciones.americana.edu.co/index.php/pensamientoamericano/index 
efectuada directamente o no y para esto un ejemplo muy claro puede ser el juego de la ruleta rusa, que se trata de que el jugador coloca una bala dentro del tambor de una pistola y le pone a girar para no saber en qué momento esta saldrá y podrá dispararle.

Este juego es muy similar con el dolo eventual ya que en ambos se deja al azar el resultado de los hechos.

\section{La culpa en accidentes de tránsito}

Debido a la gran cantidad de actividades que se presentan en la sociedad, y que en un momento dado pueden atentar contra la organización social, el Estado se ve en la necesidad, no solamente de generar formas básicas de protección de los bienes jurídicos mediante la prohibición de conductas comisivas $\mathrm{u}$ omisivas que vayan dirigidas a su lesión o puesta en peligro, sino de sancionar aquellos proceso que, aunque no tienen dicha finalidad, suponen un alto riesgo para esos bienes jurídicos (Botero Martínez \& Álvarez Tabares , 2011).

La culpa encuentra consagración legal en Colombia en el artículo 23 de la ley 599 de 2000, que establece: "La conducta es culposa cuando el resultado típico es producto de la infracción al deber objetivo de cuidado y el agente debió haberlo previsto por ser previsible, o habiéndolo previsto, confió en poder evitarlo" (Ley 599, 2000, art. 23)

De la definición anterior se colige que la conducta culposa se compone de los siguientes aspectos:

Aspecto objetivo, comprendido como "la infracción al deber objetivo de cuidado" derivado de una imprudencia, impericia o negligencia.

Aspecto subjetivo, se refiere al sujeto activo y su capacidad de previsión del resultado dañoso.

La conducta culposa alude pues, a que el resultado típico se derive de la infracción al deber objetivo de cuidado, en conjunción, a que el sujeto activo debió haber previsto el resultado por ser previsible, o habiéndolo previsto, confió en poder evitarlo.

A diferencia del tipo doloso, en el tipo culposo el agente no direcciona su conducta para alcanzar el fin prohibido. El autor persigue un fin lícito, pero lo hace por medio de una conducta negligente o imprudente. Podemos decir, en consecuencia, que "el tipo culposo no castiga al autor por la forma en que un fin es perseguido, sino porque el resultado distinto al fin presupone de parte del causante un peligro prohibido previsible y evitable, y ello se explica porque la mera creación de un peligro no es suficiente para la imputación culposa” (Zaffaroni, 2002).

Es por esto que podemos definir que se actúa con culpa cuando se genera un resultado no buscado por el actor, es decir cuando el actor no tiene la intención o voluntad de realizar el hecho punible, pero más sin embargo este se da. Ejemplo:

Un conductor que atropella a un peatón por estar distraído mirando para otro lado. en este, se comete el atropello, pero esa no era la intención del conductor, más sin embargo su error fue no estar concentrado en la actividad que realizaba.

\section{Elementos de la culpa}

Así como el dolo posee elementos característicos, conocimiento y voluntad, la culpa exige el examen de elementos a efectos de no ser confundida con la primera modalidad de la conducta.

a) Resultado. El resultado constituye una limitación en el tipo objetivo del delito culposo. No hay tipo culposo sin resultado. De todos modos, cabe resaltar que lo jurídicamente desvalorado es la conducta. (Zaffaroni, Alagia \& Slokar, 2003).

b) Violación al deber de cuidado. El deber de cuidado, dice Tenca:

Opera como un componente normativo del tipo culposo. No existe un deber de cuidado genérico, 
de modo tal que cada conducta conlleva el suyo. Claro que para saber cuál es el deber de cuidado de la conducta, primero tenemos que conocer cuál es la conducta final del agente. (Tenca, 2010)

El resultado típico que se produzca como consecuencia de la violación al deber objetivo de cuidado es lo que presupone el hecho de encontrarnos ante un tipo culposo. Es decir, siempre debe de existir el resultado y la violación de deber de cuidado para que se pueda juzgar como culpa.

\section{Culpa sin representación}

Esta, se presenta cuando el sujeto activo obra con violación al deber objetivo de cuidado bien sea por imprudencia, impericia, o negligencia y, no prevé o se representa si quiera el resultado delictuoso de su actuar.

\section{Culpa con representación}

También denominada culpa consciente, se presenta cuando el sujeto se ha representado el resultado de su actuar, pero confía en evitar dicho resultado representado.... Señala Tenca:

En la culpa consciente, el agente actúa con conocimiento que pone en peligro un bien jurídico determinado. Generalmente la fórmula se completa señalando que, no obstante, ello, el autor confía en que el resultado no se producirá. Esto último, se dice, es lo que diferencia a la culpa consciente del dolo eventual. (Tenca, 2010).

El agente cuenta con los elementos necesarios para representarse el resultado (previsibilidad) pero no lo hace. La culpa consciente es un defecto del querer, pues el autor actúa pese a haber previsto la posibilidad de configuración del tipo. (Tenca, 2010).

Es decir que en estos casos el actor sabe que, si comete $\mathrm{x}$ o $\mathrm{y}$ acto puede causar $\mathrm{u}$ daño, pero lo hace pensando que puede evadir este. Bien sea que el resultado se produzca con o sin la representación del agente, el tipo culposo acaece por alguna de las siguientes actitudes de personalidad del sujeto activo.

\section{Dolo eventual y culpa consciente}

A pesar de que en el plano puramente teórico la diferenciación entre conductas dolosas y culposas puede parecer diáfana - quien conoce y quiere la realización de los elementos objetivos del tipo actúa dolosamente; si falta el segundo de estos elementos, el querer, el comportamiento podrá imputarse subjetivamente, a lo sumo, de culposo - en la cotidianidad acaecen numerosas situaciones - sujetos que bajo el influjo de bebidas alcohólicas irresponsablemente conducen vehículos que causan resultados fatales - en las que determinar si el autor realizó el hecho con conocimiento y voluntad no resulta ya tan sencillo. La existencia en la práctica de esta “zona gris" se sitúa alrededor de la frontera entre el dolo eventual y la culpa consciente.

Como se reseñó precedentemente, tratándose de tipicidad subjetiva se suscita un gran debate que no ha dejado de llamar la atención de los más reconocidos dogmáticos, nacionales e internacionales, ello, porque hay quienes conjeturan respecto de resultados típicos y antijurídicos sometidos a eventualidades o, porque hay quienes sugieren que ciertos sujetos pueden tornarse indiferentes frente a lesiones de bienes jurídicos ajenos. Oigamos al profesor Tenca: el estudio del dolo eventual es sumamente complejo. Quizá lo menos original que podríamos decir al respecto es que se trata de uno de los temas más difíciles de resolver para la dogmática penal, que su delimitación siempre ha resultado problemática o frases similares, pues es lo que dicen todos los autores cuando analizan el tema. (Tenca, 2010)

El término dolo eventual de todas formas es reconocido por gran parte de la doctrina como incorrecta, ya que el dolo, como voluntad de acción realizadora del plan, precisamente no es "eventual", sino por el contrario incondicional, puesto que el sujeto quiere ejecutar su proyecto incluso al precio de la realización del tipo. Únicamente la producción del resultado, y

Pensamiento Americano Vol. 13 - No. 26 - p.p. 51-61 • 2020 • Julio-Diciembre • Corporación Universitaria Americana · Barranquilla, Colombia • ISSN: 2027-2448 
no el dolo, depende de eventualidades o condiciones inciertas. Sería por lo tanto más correcto hablar de un dolo, sobre la base de hechos de cuya inseguridad es consciente. En párrafos precedentes habíamos mencionado la diferencia de índole punitiva que separa al dolo eventual con la culpa consciente y ello es así ya que quien incluye en sus cálculos la realización de un tipo reconocida por él como posible, sin que la misma le disuada de su plan, se ha decidido conscientemente - aunque sólo sea para el caso eventual y a menudo en contra de sus propias esperanzas de evitarlo-en contra del bien jurídico protegido - y esta decisión por la posible lesión de bienes jurídicos, es la que diferencia al dolo eventual en su contenido de desvalor de la imprudencia consciente y la que justifica su más severa punición-. (Letner, 2010)

Sin lugar a duda el dolo eventual no es tema de poca monta, por el contrario, ha dinamizado la teoría del delito, sin embargo, lo que se pretende desarrollar - demostrar no son muletillas retóricas y reproducción de teorías que legitiman la aplicación de este, al contrario, la pretensión ineludible se dirige a deslegitimar el dolo eventual, vislumbrando que a pesar de los esfuerzos retóricos por llenarlo de contenido y caracterizarlo, no es más que un sofisma teórico en perjuicio de la dogmática penal demoliberal, más aún, constituye una propuesta teórica indemostrable, nutrida de hipótesis que propenden por desvirtuar, sin éxito jurídico pero si político criminal, lo que ontológica y objetivamente se debe atribuir al sujeto que causa un resultado pronosticando la eventual lesión de un bien jurídico ajeno, máxime cuando dicho sujeto habiendo ingerido alcohol opta por conducir vehículo causando la muerte de conductores y/o transeúntes, ello no es otra cosa que culpa consciente. Así pues, apelando a las nuevas fenomenologías del riesgo, el dolo eventual, teniendo la estructura de la culpa consciente es legitimado por muchos, por los efectos punitivos y políticos que genera.

\section{El querer y el desear}

Querer debe ser la acción, el movimiento corporal voluntario mismo... ciertamente, hacen falta criterios externos para determinar cuándo podemos decir que una acción determinada es o no dolosa (Vives Antón, 2011), esto debido a que el querer cometer el hecho es lo que diferencia una acción de otra.

Esos criterios externos de que habla el Maestro catalán no resultan inacabados, sin embargo, las circunstancias modales, temporales, espaciales, precedentes y posteriores de un hecho, pueden llevar a colegir la existencia o no de dolo en una acción corporal humana.

Apropósito del por qué interesa saber el querer en la producción un resultado el citado maestro expresa: la acción humana no solo está relacionada con lo que llamamos "saber, "pensar", "creer", "comprender", etc., sino que hay otra constelación de expresiones, cuyo parentesco se pone de manifiesto con la sola mención como "voluntario" o "voluntariedad", "deseo", "intención”, "propósito" y otras afines cuyo uso precisa ser analizado... calificamos la acción como voluntaria cuando queremos atribuirle un mérito o un demerito( esto es, cuando podemos valorar su conformidad o disconformidad con la norma); lo que comporta que no se use "voluntaria" para designar lo opuesto a "involuntario" (que sería intencional o dolosa) y, por lo tanto, que deba entenderse independientemente de cualquier referencia a un acto interno de la voluntad, es decir a un proceso mental que, por definición, falta en los casos de culpa inconsciente (Vives Antón, 2011).

El querer es por definición un verbo activo (tener decisión o voluntad de ejecutar una cosa), mientras que el desear es pasivo (anhelar que suceda o deje de suceder algo).

En el querer hay una voluntad direccionada a obtener un fin determinado, sin que obste a ello que algunas de las consecuencias puedan no ser deseadas. (Tenca, 2010)

El querer, aunque se redunde, es un elemento esencial del dolo propiamente dicho, que algunos llaman elemento volitivo, o conato y sin este, el querer,

Pensamiento Americano Vol. 13 - No. 26 - p.p. 51-61 • 2020 • Julio-Diciembre • Corporación Universitaria Americana · Barranquilla, Colombia • ISSN: 2027-2448 http://publicaciones.americana.edu.co/index.php/pensamientoamericano/index 
el resultado producido, jamás podrá imputarse subjetivamente a título doloso.

El dolo eventual es una invención y en realidad no se trata más que de un tipo culposo, en su modalidad de culpa con representación. De modo que es equívoco señalar que por dificultad probatoria se aplique la pena del delito culposo a casos de dolo eventual.

En definitiva, el dolo eventual no supera el marco conceptual. En el obrar doloso la voluntad del autor tiene que dirigirse a la realización del hecho típico no de una manera impersonal sino como su propia obra, su plan de autor o conocido iter criminis integrado por: la ideación, planificación, tentativa, consumación y agotamiento.

\section{CONCLUSIÓN}

La estructura del dolo es clara, conocimiento - de los elementos del tipo objetivo - y voluntad (de querer incurrir en ellos, esencialmente en el resultado) todo aquello que no contenga los antes mencionados elementos, por más esfuerzos que se quieran realizar, nunca constituirán el dolo propiamente dicho.

La diferencia entre el dolo eventual y la culpa consciente depende de un ejercicio metafísico imposible de ser constatado por la praxis judicial.

El dolo eventual es una creación dogmática en perjuicio del imputado, que contraviene todos los principios del derecho penal en un Estado Social y Democrático de Derecho, habida cuenta que, teniendo la estructura del tipo culposo se le aplica, cuando el reclamo social llama a la aplicación de una pena severa.

En la práctica, cuando las conductas culposas causan resultados de gran impacto social la pena del delito culposo resulta insignificante y no cumple, en consecuencia, su función de prevención general positiva. En esos casos, se recurre al dolo eventual, que opera como un ilegítimo correctivo político criminal, pues teniendo la estructura del tipo culposo se aplica la pena del delito doloso.
Siguiendo entonces el hilo conductor de nuestra investigación y tratando de realizar un análisis exhaustivo de lo que es el dolo y la culpa, podemos llegar a la conclusión de que estas nunca se deben, ni pueden ver como conductas semejantes ya que desde nuestro punto de vista y según lo expresado por muchos autores. cada uno tiene su punta y definición claras, pero también su punto más importante. y lo que diferencia la una de la otra es la intención con la que se cometen lo hecho punitivo, ese querer del ser humano en cometer o no cometer el hecho, esa línea entre lo que el autor quiere y lo que no quiere. Este que, aunque parezca mínimo, puede llegar a definir la forma en la que se debe de juzgar a un ser humano.

Es por esto, que nosotros concluimos diciendo que en el caso de las personas que cometen homicidios con ocasión de su estado de embriaguez, la imputación subjetiva debería ser a título de culpa con representación, mas no a título de dolo como lo ha considerado la corte, ya que para nosotros esto sería afirmar que toda aquella persona que se embriaga, lo hace premeditando o considerando la posibilidad de matar a alguien.

Finalmente, por más elaboraciones retóricas, jamás debe perderse de vista que: dolo es dolo y culpa es culpa. 


\section{Referencias}

Agudelo Betancur, N. (2004). Embriaguez y responsabilidad penal: aspectos jurídicos de la embriaguez patológica y de la embriaguez aguda. Bogotá: Universidad Externado.

Botero Martínez, J. \& Álvarez Tabares, S. (2011). La estructura típica de comisión culposa. En Derecho penal parte general - fundamentos. (pág. 714). Medellín: Universidad de Medellín.

Congreso de Colombia. (19 de diciembre de 2013). Por medio de la cual se dictan disposiciones penales y administrativas para sancionar la conducción bajo el influjo del alcohol u otras sustancias psicoactivas. (Ley 1696 de 2013). DO: 49.009

Congreso de Colombia. (24 de julio del 2000). Código penal. (Ley 599 del 2000). DO: 44.097

Corte Suprema de Justicia (25 de agosto del 2010). Proceso 32964 de 2010, M.P. Dr. José Leónidas Bustos Martínez.

Hassemer, W., Muñoz Conde, F., \& Díaz Pita, M. d. (1999). Persona, mundo y responsabilidad: bases para una teoría de la imputación en derecho penal. Bogotá, Colombia: Temis.

Letner, A. (2010). Dolo eventual y culpa con representación. (Problemas y consecuencias que traen aparejadas su distinción y su posterior aplicación en casos vinculados con el tráfico automotor). Recuperado de: http://armasmorel.cl/derechopenal/dolo-eventual-y-culpa-con-representacion.pdf

Ordeig, G. (1972). Acerca del dolo eventual. Nuevo pensamiento penal, 377.

Tenca, A. M. (2010). Dolo Eventual. Buenos Aires, Argentina: Astrea.

Vives Antón, T. (2011). Fundamentos del Sistema Penal. Valencia, España: Tiran lo blanch.

Welzel, H. (1956a). Derecho Penal. Buenos Aires, Argentina.

Welzel, H. (1956b). Derecho penal alemán. Buenos Aires, Argentina.
Zaffaroni, E. R. (2002). Derecho Penal General. Buenos Aires, Argentina: Fondo de Cultura Económica.

Zaffaroni, E. R. (2011). Estructura básica de derecho penal. Buenos Aires, Argentina: Ediar.

Zaffaroni, E. R., Alagia, A. \& Slokar, A. (2003). Manual de derecho penal. Parte general. Buenos Aires, Argentina: Ediar.

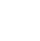

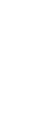

:


